\title{
Information Overload in Emergency Medicine Physicians: A Multisite Case Study Exploring the Causes, Impact, and Solutions in Four North England National Health Service Trusts
}

Laura Sbaffi ${ }^{1}$, BSc, MSc, MA, DPhil; James Walton ${ }^{2}$, BSc, MBChB, MRCEM, FRCEM; John Blenkinsopp ${ }^{3}$, BA (Hons); Graham Walton ${ }^{4}$, BSc, MA, MBA, DPhil

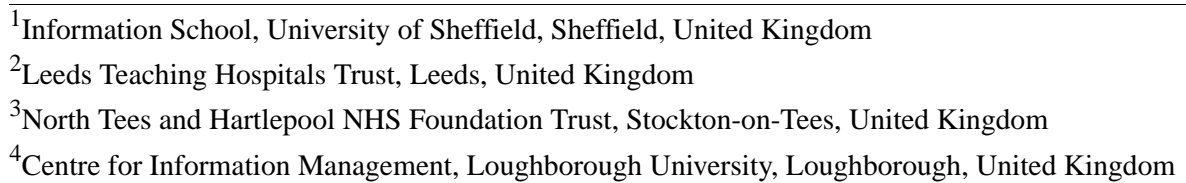

\section{Corresponding Author:}

Laura Sbaffi, BSc, MSc, MA, DPhil

Information School

University of Sheffield

211 Portobello Street

Regent Court

Sheffield, S1 4DP

United Kingdom

Phone: 441142222686

Email: L.Sbaffi@sheffield.ac.uk

\section{Abstract}

Background: Information overload is affecting modern society now more than ever because of the wide and increasing distribution of digital technologies. Social media, emails, and online communications among others infuse a sense of urgency as information must be read, produced, and exchanged almost instantaneously. Emergency medicine is a medical specialty that is particularly affected by information overload with consequences on patient care that are difficult to quantify and address. Understanding the current causes of medical information overload, their impact on patient care, and strategies to handle the inflow of constant information is crucial to alleviating stress and anxiety that is already crippling the profession.

Objective: This study aims to identify and evaluate the main causes and sources of medical information overload, as experienced by emergency medicine physicians in selected National Health Service (NHS) trusts in the United Kingdom.

Methods: This study used a quantitative, survey-based data collection approach including close- and open-ended questions. A web-based survey was distributed to emergency physicians to assess the impact of medical information overload on their jobs. In total, 101 valid responses were collected from 4 NHS trusts in north England. Descriptive statistics, principal component analysis, independent sample two-tailed $t$ tests, and one-way between-group analysis of variance with post hoc tests were performed on the data. Open-ended questions were analyzed using thematic analysis to identify key topics.

Results: The vast majority of respondents agreed that information overload is a serious issue in emergency medicine, and it increases with time. The always available culture (mean 5.40, SD 1.56), email handling (mean 4.86, SD 1.80), and multidisciplinary communications (mean 4.51, SD 1.61) are the 3 main reasons leading to information overload. Due to this, emergency physicians experience guideline fatigue, stress and tension, longer working hours, and impaired decision making, among other issues. Aspects of information overload are also reported to have different impacts on physicians depending on demographic factors such as age, years spent in emergency medicine, and level of employment.

Conclusions: There is a serious concern regarding information overload in emergency medicine. Participants identified a considerable number of daily causes affecting their job, particularly the traditional culture of emergency departments being always available on the ward, exacerbated by email and other forms of communication necessary to maintain optimal, evidence-based practice standards. However, not all information is unwelcome, as physicians also need to stay updated with the latest guidelines on conditions and treatment, and communicate with larger medical teams to provide quality care. 
(J Med Internet Res 2020;22(7):e19126) doi: 10.2196/19126

\section{KEYWORDS}

emergency medicine; information overload; physicians; national health care system

\section{Introduction}

\section{Background}

The concept of information overload has existed long before the term was first defined in the 20th century. The writer of Ecclesiastes 12:12 in the third century before Christ was complaining that "of making books there is no end." In the first century, Anno Domini, the Roman philosopher Seneca noted how "the abundance of books is distraction" [1]. Hence, information overload has been experienced by people long before the appearance of today's digital gadgets and social media in the work environment and at home. Most people appreciate the freedom that comes with choice and the many channels of media that saturate the information world. However, a 2016 Pew Research Center survey [2] showed that around 20\% of the American population experienced overload and unease in looking for information. According to this study, those with more access to the internet are more likely to express worries about information overload and report difficulty in finding the information they need. Moreover, many institutions such as government agencies, schools, banks, and health care services require a lot of data and information gathering from their customers to process their requests, which contributes to stress and anxiety [2]. In the United Kingdom, a recent survey conducted by TeleWare on 2000 employees revealed that $36 \%$ of employees admitted that they had wasted a lot of their working day attempting to resolve an issue where they have forgotten valuable information. A similar number (34\%) explained that forgetting information has led them to deal ineffectively with customers, suppliers, or clients. Around a quarter have missed important deadlines $(26 \%)$ or let their colleagues down (25\%) because they did not have the necessary information in the front of their mind [3].

The idea of having every piece of information at hand in any given situation is undoubtedly tempting and, in critical working situations, mandatory [4]. However, this is becoming increasingly unrealistic because of the large volume of data and information. An understanding of the current situation may be gathered by setting information overload in the theoretical framework provided by Floridi [5], whose view entails the definition of 3 main periods in the advancement of humanity: prehistory, before recorded information; history, when society was aided by recorded information; and hyperhistory, where society is shaped and dependent on information and communication technologies. The spreading of the onlife human condition, whereby lives are lived both online and offline in an infosphere, mirrors the progression of society through hyperhistory. This drastic shift in how people perceive their existence has raised a number of issues, including information overload in a more contemporary, Information and Communication Technology (ICT)-centered lens.

This study aimed to explore the impact of information overload on emergency medicine physicians (EMPs) working across 4
National Health Service (NHS) trusts in north England. The focus was to explore physicians' views on the impact of information overload, including the extent of the impact, whether it had increased, and whether any preventative measures were taken to address information overload. The cross-disciplinary research team included an EMP, 2 academics, and an NHS clinical effectiveness adviser who oversaw the study.

\section{Literature Review}

\section{Information Overload in the Workplace}

The concept of information overload became generally known in the early 1970s, after the publication of Toffler's book on society's deep organizational changes destined to cause shock and disorientation in people [6]. This initial idea of information overload refers to the difficulty a person can have understanding an issue and making errors caused by the presence of too much information. A later interpretation of the concept, in the 1990s, saw information overload defined as "occurring when the information processing demands on an individual's time to perform interactions and internal calculations exceed the supply or capacity of time available for such processing" [7].

Recent research has demonstrated how there cannot be a unifying definition of the concept, as the context in which it is used changes all the time [8,9]. There is however an agreement that information overload occurs when the information received becomes a burden rather than a help for users [10]. A survey conducted in 2016 by the Chartered Institute of Management Accountants showed how information overload was the main contributor to poor decision making in business globally [11]. Together with weakened decision making, information overload can also lead people to feel unnecessarily overwhelmed and stressed. Recent research has shown that people presenting with large amounts of information while performing search tasks tend to experience a sense of being overwhelmed and even display an increased heart rate, which leads to increased stress levels [12]. In the workplace environment, information overload can lead to a lack of engagement and loss of productivity [13-15]. The increase in mobile technologies has exacerbated this issue. The overload effects associated with the use of mobile information technologies in the workplace have become increasingly dominant and can translate into a considerable reduction in job satisfaction $[16,17]$. This is mostly because of the perception of immediacy that people have in connection with such devices. It is assumed that emails, text messages, and notifications should be read and answered quickly [18]. Several studies have demonstrated that training in an email or a social media protocol can be effective as a means to reduce information overload [9,19]. Interestingly, people of all ages and backgrounds are affected by this problem in every aspect of their working (and personal) life [9]. However, the same authors stated how the literature tends to focus on the workplace as a whole rather than on job specifications and particular skills 
required in certain occupations. The same view is shared by Kalman [20], who stated that "the workplace pressures attributed to information overload are very real, the concept itself is vague and poorly defined.". It is however worth noting that recent research has shown how information overload has the potential to enhance people's cognitive abilities and help them process more information in less time, particularly if the right visualization tools (eg, charts and tables instead of text) are applied in the correct contexts [21]. There are benefits in assimilating larger amounts of information, and the human mind can adapt in time to the increased influx, but it is also bound to manifest side effects such as psychological disturbances and neurological problems along the way [22].

\section{Information Overload and Health Care Professionals}

When health care professionals experience information overload, at least one extra layer of concern must be taken into account: the consequence on patient care. Several studies have looked at the effects of information overload on nurses [23,24]; however, few have focused on information overload as experienced in general by health care professionals [25-27] and even less have approached the impact on patient care. Laker et al [28] argued how it could prevent practitioners from seeing the most important details while examining patients. Nevertheless, it is not the right information that is overwhelming, as that, if readily available at the point of care, would lead to effective patient care. It is the background noise information and other confounding factors (eg, multiple sources of information and conflicting or irrelevant information) that cause disruptions [29].

Klerings et al [27] agreed with this view and suggested solutions to overcome information overload and manage both health care information and patient care effectively. They mentioned different solutions based on the main overload trigger mechanisms, such as "technological solutions; creation or adaption of specific content types; improving health literacy; and creating or strengthening the roles of human intermediaries."

Most likely, the situation is destined to get worse in this era of information expansion. As Yamamoto explained in 2016 [30], health care professionals are already overloaded by the information currently available, but the circumstances will worsen because of 3 key aspects: (1) the need to stay up to date from a technological and knowledge-based point of view; (2) the diversification of medical needs resulting in the growth of the medical practice; and (3) the rapid and constant changes in the health care environment. Digital technologies are proving to be both a curse and a blessing. On the one hand, they represent yet another source of-often unwanted information [31] — but, on the other hand, they can support physicians in the detection of adverse events and patients at risk of deterioration with the potential to improve health outcomes [32]. This is only achievable if, when planning and implementing digital information solutions in hospitals and clinics, factors such as the provision of clinical training, resources to cope with the additional workload, and optimization of algorithms to reduce superfluous alerts are taken into consideration [32].

In particular, emergency physicians are exposed to further burdens with the need for fast decision making [33], interruptions [34], multitasking [34], and highly variable workloads [35]. Emergency medicine is "a form of medical treatment and aid which seeks to treat unexpected, acute illnesses that pose grave threats to life" [36]. The urgent dimension typical of emergency departments requires doctors to be constantly vigilant, highly reactive, and mentally lucid throughout often very long work shifts [37]. This highly pressurized environment leads to occupational stress, often with negative consequences for doctors' mental and physical health and work efficiency, which can lead to mistakes in diagnoses and patient treatments [38]. Chronic workplace stress has been identified by the World Health Organization (WHO) as the leading cause of burnout syndrome [39]. According to the WHO, the syndrome is characterized by the following 3 main aspects: feelings of exhaustion, feelings of negativism toward one's job, and reduced professional effectiveness [39]. A considerable body of literature has demonstrated that there is a higher prevalence of burnout among emergency physicians compared with other medical professions and specialties [36,40-42]. It is also evident that information overload plays a determinant role in exacerbating burnout in the medical profession $[43,44]$. However, only 1 study, conducted by Walton [45] on hospital doctors and pharmacists, has considered the impact of information overload beyond burnout on hospital medical staff. The complex setting in which emergency physicians act and operate requires a better understanding of the impact of information overload on their practice and its implications for both patient care, work efficiency, and work/life balance. To the authors' knowledge, no empirical research has been conducted on information overload as experienced by EMPs specifically and according to different roles, age, and level of seniority; therefore, this paper hopes to serve as a pathbreaker for future studies.

\section{Aim and Objectives}

This study aimed to identify and assess the main causes and sources of medical information overload as experienced by EMPs. Specifically, the research objectives (ROs) were as follows:

1. RO1: Determine the extent to which EMPs experience medical information overload.

2. RO2: Establish the contributory factors to information overload and evaluate their impact on physicians' working lives.

3. RO3: Identify the coping mechanisms adopted by EMPs to respond to information overload.

4. RO4: Explore whether EMPs at different career stages respond to information overload in different ways.

5. RO5: Determine the impact of physicians' information overload on patient care.

\section{Methods}

\section{Data Collection}

The assessment of EMPs' experience with information overload was undertaken using a survey-based primary data collection tool. This was a multicenter study covering 4 NHS trusts in north England, which had approached the staff in their emergency departments and asked them to complete a 
web-based survey over a period of 3 months in the summer of 2019. All eligible doctors from the trusts were sent an email inviting them to participate in the study. The opening page of the survey included an information sheet and a consent form. Participants were not able to proceed with the survey unless they had ticked the consent option. The study followed the NHS Health Research Authority protocol and was granted both the NHS Research Ethics Committee and the University of Sheffield ethics approvals. The survey, designed using LimeSurvey $\mathrm{GmbH}$, took approximately $10 \mathrm{~min}$ to complete and was divided into 2 main sections: the first related to demographics and the second addressing emergency physicians' views on medical information overload, opening with a definition of information overload to guarantee the homogeneity of interpretation. This section was composed of 42 Likert scale-like questions, comprising 2 overarching questions and 4 main aspects of information overload: (1) impact rating of individual information overload sources, (2) impact of information overload on specific work/life aspects, (3) preventative measures to manage information overload, and (4) useful sources of medical information. This part included statements such as "I feel that information overload significantly impacts on my work" and "E-mails I receive are a major contributing factor to my feelings of information overload" rated on a scale from 1 (completely disagree) to 7 (completely agree). There were also 7 open-ended questions to allow the respondents to elaborate on their opinions and perceptions. Most of the statements in the survey were extracted from a literature review conducted by Hall and Walton [8] and from a subsequent survey that one of the authors of this paper (GW) administered to hospital pharmacists and doctors in 2013 [45]. The remaining statements have been informed by 2 other authors (JW and JB) who are directly involved in emergency medicine and are aware of the current main sources of information overload in this sector. In total, the survey invite was sent to 263 physicians; 164 respondents participated with 101 recording full responses (38\% response rate), which were then selected for analysis, as 63 records only contained partial demographic information and were deemed unusable.

\section{Data Analysis}

All data were saved in an IBM SPSS version 26 file for analysis. The dataset was initially inspected for errors and out-of-range values for each variable. The demographics were then produced to profile the sample. Next, descriptive statistics were performed for the Likert-style questions in the main section of the survey; means and standard deviations were calculated for each of the statements. A principal component analysis (PCA) was performed on the survey statements related to the sources of information overload. Finally, independent samples $t$ tests and one-way between-group analyses of variance (ANOVAs) with Hochberg GT2 post hoc tests were conducted to compare mean scores in relation to respondents' demographics (ie, the current level of employment, age, and the number of years in emergency medicine). The analyses performed in terms of gender and NHS trust did not show any differences between groups; hence, they are not reported here.

In addition, the open-ended questions and closing remarks were manually coded independently by 2 members of the research team using the 6-step approach to thematic analysis by Braun and Clarke [46].

\section{Results}

\section{Sample Demographic Profile}

This section provides a summary of the demographic characteristics of the respondents. The sample shows a relatively balanced distribution between doctors working as junior trainees $(31 / 101,30.7 \%)$, senior trainees $(28 / 101,27.7 \%)$, and consultants $(29 / 101,28.7 \%)$, whereas $12.9 \%$ (13/101) reported other types of working levels (Table 1). In terms of gender, $42.6 \%$ (43/101) were male and 56.4\% (57/101) were female (only $1 / 101,1 \%$, did not indicate their gender). As for age, the majority $(70 / 101,69.3 \%)$ were between 20 and 39 years, with $30.7 \%(31 / 101)$ between 40 and 59 years. In terms of the period since respondents became EMPs, two-third (68/101, 67.4\%) had been emergency physicians for 10 years or less. Finally, across the 4 NHS Foundation Trusts surveyed, 39.6\% (40/101) of respondents were based at Leeds Teaching Hospitals, followed by Bradford Teaching Hospitals (24/101, 23.7\%) and Airedale $(23 / 101,22.8 \%)$, whereas $13.9 \%$ (14/101) were based on North Tees and Hartlepool. 
Table 1. Demographic data from the respondents to the survey.

\begin{tabular}{|c|c|}
\hline Demographic characteristics & Values, $\mathrm{n}(\%)$ \\
\hline \multicolumn{2}{|l|}{ Age (years) } \\
\hline $20-29$ & $24(23.8)$ \\
\hline $30-39$ & $46(45.5)$ \\
\hline $40-49$ & $18(17.8)$ \\
\hline $50-59$ & $13(12.9)$ \\
\hline \multicolumn{2}{|l|}{ Gender } \\
\hline Male & $43(42.6)$ \\
\hline Female & $57(56.4)$ \\
\hline Prefer not to say & $1(1.0)$ \\
\hline \multicolumn{2}{|c|}{ How long have you been an emergency medicine physician for? (years) } \\
\hline$<1$ & $21(20.8)$ \\
\hline $1-4$ & $25(24.8)$ \\
\hline $5-10$ & $22(21.8)$ \\
\hline $11-15$ & $16(15.8)$ \\
\hline $16-20$ & $9(8.9)$ \\
\hline$>20$ & $8(7.9)$ \\
\hline \multicolumn{2}{|l|}{ What is your current level? } \\
\hline Junior trainee $\mathrm{a}^{\mathrm{a}}$ & $31(30.7)$ \\
\hline Senior trainee ${ }^{b}$ & $28(27.7)$ \\
\hline Consultant & $29(28.7)$ \\
\hline Other $^{\mathrm{c}}$ & $13(12.9)$ \\
\hline \multicolumn{2}{|l|}{ What NHS ${ }^{d}$ trust do you work for? } \\
\hline North Tees and Hartlepool NHS Foundation Trust & $14(13.9)$ \\
\hline Bradford Teaching Hospitals NHS Foundation Trust & $24(23.7)$ \\
\hline Leeds Teaching Hospitals NHS Trust & 40 (39.6) \\
\hline Airedale NHS Foundation Trust & $23(22.8)$ \\
\hline
\end{tabular}

${ }^{\mathrm{a}}$ Foundation year, VTS, and ACCS.

${ }^{\mathrm{b}}$ ST4-ST7, staff grade, and junior clinical fellow.

${ }^{\mathrm{c}}$ Including advanced clinical practitioner and associate specialist.

${ }^{\mathrm{d}}$ NHS: National Health Service.

\section{RO1 and RO2: Emergency Physicians' Views on Medical Information Overload}

Table 2 summarizes the responses to the Likert scale statements listed in the second section of the survey in terms of mean and standard deviation. The table reports the 2 general questions asked at the beginning of the survey, and the remaining statements were divided across the 4 main information overload aspects covered in decreasing order of importance. The results suggest that there is overall agreement among emergency physicians that information overload has an impact on their work (mean 5.10, SD 1.25), and the problem has been increasing in time (mean 5.63, SD 1.34).

In terms of the sources that have the most impact on medical information overload, there is a wide range of mean values. Doctors listed the 24/7 culture (mean 5.40, SD 1.56), email handling (mean 4.86, SD 1.80), and, in equal measure, multidisciplinary communications (mean 4.51, SD 1.61) and local clinical guidelines (mean 4.50, SD 1.52). On the other hand, the information derived from patients (mean 3.29, SD 1.62), social media (mean 3.15, SD 1.88), and drug companies (mean 2.36, SD 1.50) does not pose particular concerns. 
Table 2. Emergency clinicians' perspectives on information overload.

\begin{tabular}{|c|c|}
\hline Statements ${ }^{\mathrm{a}}$ & VMean (SD) \\
\hline To what extent does medical information overload impact your work? & $5.10(1.25)$ \\
\hline To what extent do you agree that medical information overload has increased for you at work? & $5.63(1.34)$ \\
\hline \multicolumn{2}{|l|}{ Impact of each of the following causes of medical information overload } \\
\hline $24 / 7$ culture (ie, the always available workplace) & $5.40(1.56)$ \\
\hline Email & $4.86(1.80)$ \\
\hline Multidisciplinary communication & $4.51(1.61)$ \\
\hline Local clinical guidelines & $4.50(1.52)$ \\
\hline Info from employer/manager & $4.43(1.67)$ \\
\hline Evidence-based practice & $4.22(1.57)$ \\
\hline National clinical guidelines & $4.21(1.52)$ \\
\hline Info to employer/manager (eg, as part of reporting activity) & $4.14(1.67)$ \\
\hline Journal papers & $3.41(1.67)$ \\
\hline Patients bringing information & $3.29(1.62)$ \\
\hline Social media & $3.15(1.88)$ \\
\hline Drug company information & $2.36(1.50)$ \\
\hline \multicolumn{2}{|l|}{ How does medical information overload impact on the following aspects? } \\
\hline Guideline fatigue & $6.08(1.56)$ \\
\hline Stress and tension & $5.25(1.37)$ \\
\hline Longer working hours & $4.87(1.70)$ \\
\hline Impaired decision making & $4.85(1.57)$ \\
\hline Imprecise clinical judgments & $4.84(1.45)$ \\
\hline Tiredness/illness & $4.81(1.54)$ \\
\hline Decrease in social life & $4.26(1.80)$ \\
\hline \multicolumn{2}{|l|}{ What preventative measures do you adopt to combat information overload? } \\
\hline Prioritization & $6.07(1.13)$ \\
\hline Email handling skills (ie, ability to discriminate by importance) & $5.39(1.50)$ \\
\hline Effective time management & $5.30(1.22)$ \\
\hline Effective information management & $5.23(1.30)$ \\
\hline Software/hardware & $3.40(1.81)$ \\
\hline Information technology point of need delivery & $3.13(1.82)$ \\
\hline Medical librarian & $1.85(1.32)$ \\
\hline \multicolumn{2}{|l|}{ What sources do you find most useful when in need of medical information? } \\
\hline Local clinical guidelines & $6.13(1.03)$ \\
\hline National clinical guidelines & $5.80(1.09)$ \\
\hline Colleagues & $5.69(1.34)$ \\
\hline Evidence-based practice & $5.14(1.37)$ \\
\hline Multidisciplinary communication & $4.41(1.49)$ \\
\hline Journal papers & $3.54(1.39)$ \\
\hline Patients bringing information & $2.67(1.56)$ \\
\hline Social media & $2.62(1.65)$ \\
\hline Medical librarian & $2.60(1.60)$ \\
\hline Drug company information & $2.17(1.29)$ \\
\hline
\end{tabular}


${ }^{a}$ All statements were rated on a Likert scale from 1 to 7 , and the values reported here are in decreasing order of importance.

Views on the consequences of information overload on different aspects of physicians' daily job and life show a more compacted set of values (less than 2 points difference between the top and bottom entries), indicating that all listed aspects are negatively impacted. Guideline fatigue is the leading consequence of information overload (mean 6.08, SD 1.56), followed by stress and tension (mean 5.25, SD 1.37). However, longer working hours, inaccurate decision making and clinical judgment, and chronic tiredness leading to illness also returned high mean values. Physicians also complained that information overload is detrimental to their personal and social lives (mean 4.26, SD 1.80).

\section{RO3: Coping Mechanisms Adopted by Emergency Medicine Physicians to Address Information Overload}

When it comes to the adoption of preventive measures to overcome information overload, prioritization is by far the most common approach (mean 6.07, SD 1.13), closely followed by email handling (mean 5.39, SD 1.50) and time (mean 5.30, SD 1.22) and information (mean 5.23, SD 1.30) management. Conversely, external support such as information technology (IT) and ICT and clinical librarians are not considered particularly effective.

In situations of actual need for medical information, both local (mean 6.13, SD 1.03) and national (mean 5.80, SD 1.09) clinical guidelines are the 2 primary sources, which interestingly highlight the struggle doctors regularly experience. On the one hand, such guidelines are crucial to maintaining a critical level of medical knowledge, but, on the other hand, because of their sheer volume and constant updating, they represent the main cause of medical information overload. In this context, colleagues are also an important source of easily accessible and reliable medical information while on the ward (mean 5.69, SD 1.34). Patient information (mean 2.67, SD 1.56), social media (mean 2.62, SD 1.65), and drug companies (mean 2.17, SD 1.29) are considered irrelevant sources because of their unqualified or biased nature. However, medical librarians have also scored a low mean value (mean 2.60, SD 1.60), perhaps because their services were not considered to be of immediate relevance to emergency physicians' very fast case turnover.

PCA with direct oblimin rotation with Kaiser normalization was performed on the 12 statements addressing the main causes of information overload. The Kaiser-Meyer-Olkin value was 0.807 , exceeding the recommended value of 0.6 [47], and the Bartlett test of sphericity reached statistical significance $(P<.001)$, supporting the factorability of the correlation matrix. The analysis identified the presence of 3 factors explaining $42.2 \%, 12.2 \%$, and $9.6 \%$ of the variance, respectively. Table 3 reports the factors and Cronbach $\alpha$ values calculated to assess the reliability of the scale.

Table 3. Exploratory factor analysis of factors relative to causes of information overload.

\begin{tabular}{l}
\hline Factors/statements \\
\hline Factor 1: the dutiful physician \\
24/7 always available culture \\
Emails \\
Information from employer/manager \\
Information to employer/manager \\
Multidisciplinary communications \\
Factor 2: the informed physician \\
Local clinical guidelines \\
National clinical guidelines \\
Evidence-based practice \\
Factor 3: the current physician \\
Journal papers \\
Social media
\end{tabular}

The first factor, named the dutiful physician, includes the potential sources of information overload that cannot be ignored or overseen as they form part of physicians' daily administrative tasks that must be undertaken in addition to direct patient care. These tasks are demanding and time-consuming. Regular reporting to and from line managers or employers and multidisciplinary communications are crucial to the smooth running of emergency departments and provide a more coordinated approach to patient care discharge planning [48]. Most of such communications are exchanged via email, which becomes the main conduit of information overload, and are carried out at all times, hence exacerbating further the always available culture.

The second factor, named the informed physician, relates to physicians' need to stay up to date with the changes in guidelines, both at the local and national level and evidence-based practice on how health care professionals should care for patients with specific conditions, and which are based on best evidence practice. These guidelines help the standardization of care across NHS trusts and can be modified 
to adjust to local needs to provide a cost-effective approach to care [49].

The third factor, named the current physician, includes additional sources of information overload that physicians experience on a regular basis in the form of notifications and which are mostly derived from scientific publications (eg, notifications of new articles, subscription invites, and electronic book updates) and social media. The respondents' comments on this aspect have shown how there appears to be an expectation that physicians, trainees in particular, cluster in online study groups and follow relevant Twitter handles such as \#MedEd or \#FOMed.

\section{RO4: Information Overload Perceptions by Age and Years Spent in Emergency Medicine}

Independent sample $t$ tests have been undertaken on the bank of Likert scale statements in terms of age of respondents and their experience in emergency medicine. All statistically significant results are reported in Tables 4 and 5. In terms of age (Table 4), younger physicians appeared less worried about their reporting activities (mean 3.89, SD 1.02) than older ones (mean 4.65, SD 1.11). Conversely, they are more affected by the loss in social activities because of information overload (mean 4.52, SD 1.31) as opposed to more experienced physicians (mean 3.68, SD 1.05). In addition, younger physicians reported a higher rate of impaired decision making (mean 5.19, SD 1.40) and imprecise clinical judgments (mean 5.12, SD 1.18) than their older colleagues (mean 4.07, SD 1.14 and mean 4.23, SD 1.37), who are still concerned about their performance but have greater experience to draw upon. Younger physicians also seem to rely more on local clinical guidelines (mean 6.28, SD 1.08) than older ones (mean 5.81, SD 1.23) to reduce decision fatigue.

Table 4. Independent samples $t$ tests on the age of respondents.

\begin{tabular}{|c|c|c|c|c|c|c|}
\hline Questions & $t$ test $(d f)$ & $P$ value & Mean difference & $\begin{array}{l}\text { Age ( } 20-39 \text { years), } \\
\text { mean }(\mathrm{SD})\end{array}$ & $\begin{array}{l}\text { Age ( } 40-59 \text { years), } \\
\text { mean }(\mathrm{SD})\end{array}$ & Total mean \\
\hline $\begin{array}{l}\text { Impact of info to employer/manager } \\
\text { (eg, as part of reporting activity) on } \\
\text { medical information overload }\end{array}$ & $-2.109(94)$ & .04 & 0.75 & $3.89(1.02)$ & $4.65(1.11)$ & 4.14 \\
\hline $\begin{array}{l}\text { How does medical information } \\
\text { overload impact on decrease in so- } \\
\text { cial life? }\end{array}$ & $2.098(51.011)$ & .04 & 0.84 & $4.52(1.31)$ & $3.68(1.05)$ & 4.26 \\
\hline $\begin{array}{l}\text { How does medical information } \\
\text { overload impact on impaired deci- } \\
\text { sion making? }\end{array}$ & $3.304(50.699)$ & .002 & 1.12 & $5.19(1.40)$ & $4.07(1.14)$ & 4.85 \\
\hline $\begin{array}{l}\text { How does medical information } \\
\text { overload impact on imprecise clini- } \\
\text { cal judgments? }\end{array}$ & $2.762(49.767)$ & .008 & 0.89 & $5.12(1.18)$ & $4.23(1.37)$ & 4.84 \\
\hline $\begin{array}{l}\text { What preventative measures do you } \\
\text { adopt to combat information over- } \\
\text { load? Email handling skills (ie, } \\
\text { ability to discriminate by impor- } \\
\text { tance) }\end{array}$ & $-2.055(70.489)$ & .04 & 0.61 & $5.19(1.22)$ & $5.81(1.18)$ & 5.39 \\
\hline $\begin{array}{l}\text { What sources do you find most use- } \\
\text { ful when in need of medical informa- } \\
\text { tion? Local clinical guidelines }\end{array}$ & $2.198(60.325)$ & .03 & 0.47 & $6.28(1.08)$ & $5.81(1.23)$ & 6.13 \\
\hline
\end{tabular}

In terms of years of experience in emergency medicine (Table 5 ), the only dissimilarity seems to relate to the impact and handling of work emails. Physicians with more than 10 years of experience identify the number of emails received as one of the main causes of information overload (mean 5.39, SD 1.19) as opposed to physicians with less experience who scored a mean of 4.60 (SD 1.26) and hence attributed more importance to email handling skills as a way to manage the problem (mean of 6.03 and SD 1.15 against a mean of 5.06 and SD 1.13 reported for less experienced physicians). 
Table 5. Independent samples $t$ tests on the years spent in emergency medicine.

\begin{tabular}{lllllll}
\hline Questions & $t$ test $(d f)$ & $P$ value & $\begin{array}{l}\text { Mean dif- } \\
\text { ference }\end{array}$ & $\begin{array}{l}\text { Years of experience (0-10 years), } \\
\text { mean (SD) }\end{array}$ & $\begin{array}{l}\text { Years of experience (more than 10 years), } \\
\text { mean (SD) }\end{array}$ & $\begin{array}{l}\text { Total } \\
\text { mean }\end{array}$ \\
\hline $\begin{array}{l}\text { Impact of emails } \\
\text { on information } \\
\text { overload }\end{array}$ & $\begin{array}{l}-2.134 \\
(65.084)\end{array}$ & .04 & 0.79 & $4.60(1.26)$ & $5.39(1.19)$ \\
$\begin{array}{l}\text { What preventative } \\
\text { measures do you } \\
\text { adopt to combat } \\
\text { information over- } \\
\text { load? Email han- } \\
\text { dling skills (ie, } \\
\text { ability to discrimi- }\end{array}$ \\
$\begin{array}{l}\text { nate by impor- } \\
\text { tance) }\end{array}$
\end{tabular}

\section{RO4: Information Overload Perceptions by Level of Employment}

To conclude the quantitative assessment of the data collected, one-way between-group ANOVAs by the level of employment were also performed on the survey statements (Table 6). Across the 3 main levels populating emergency departments, senior trainees and consultants are those acknowledging the increased information overload with time the most, possibly because of their longer service in hospitals. However, in relation to other aspects, senior trainees seem to experience the most difficulties. For example, in terms of the aspects of their work and life impacted by information overload, they complain about a decrease in social life and diminished decision-making abilities.

Table 6. One-way between-group analysis of variance on current level of employment.

\begin{tabular}{|c|c|c|c|c|c|c|}
\hline Questions & $F$ test & $P$ value & Junior trainee, mean $(\mathrm{SD})$ & Senior trainee, mean (SD) & Consultant, mean (SD) & Total mean \\
\hline $\begin{array}{l}\text { To what extent do you } \\
\text { agree that medical infor- } \\
\text { mation overload has in- } \\
\text { creased for you at work? }\end{array}$ & 5.798 & .004 & $5.07^{\mathrm{a}, \mathrm{b}}(1.01)$ & $6.07^{\mathrm{a}}(1.02)$ & $6.03^{\mathrm{b}}(1.22)$ & 5.63 \\
\hline $\begin{array}{l}\text { How does medical infor- } \\
\text { mation overload impact } \\
\text { on decrease in social life? }\end{array}$ & 3.249 & .04 & $4.50(1.27)$ & $4.79^{\mathrm{c}}(1.06)$ & $3.72^{\mathrm{c}}(1.36)$ & 4.26 \\
\hline $\begin{array}{l}\text { How does medical infor- } \\
\text { mation overload impact } \\
\text { on impaired decision } \\
\text { making? }\end{array}$ & 4.331 & .02 & $5.17(1.14)$ & $5.36^{\mathrm{c}}(1.14)$ & $4.29^{\mathrm{c}}(1.40)$ & 4.85 \\
\hline $\begin{array}{l}\text { What preventative mea- } \\
\text { sures do you adopt to } \\
\text { combat information } \\
\text { overload? Email handling } \\
\text { skills (ie, ability to dis- } \\
\text { criminate by importance) }\end{array}$ & 9.223 & $<.001$ & $5.47(1.16)$ & $4.67^{\mathrm{c}}(1.18)$ & $6.10^{\mathrm{c}}(1.01)$ & 5.39 \\
\hline $\begin{array}{l}\text { What sources do you find } \\
\text { most useful when in need } \\
\text { of medical information? } \\
\text { Social media }\end{array}$ & 9.246 & $<.001$ & $2.03^{\mathrm{a}}(1.21)$ & $3.59^{\mathrm{a}, \mathrm{c}}(1.02)$ & $2.23^{\mathrm{c}}(1.19)$ & 2.62 \\
\hline
\end{tabular}

${ }^{\mathrm{a}}$ Junior trainee versus senior trainee.

${ }^{\mathrm{b}}$ Junior trainee versus consultant.

${ }^{\mathrm{c}}$ Senior trainee versus consultant.

In addition, whereas for consultants, the ability to effectively manage work emails is crucial to handle, at least partially, information overload (mean 6.10, SD 1.01), senior trainees are the least concerned about this aspect (mean 4.67, SD 1.18). Finally, although the use of social media as a source of medical information is not a very popular choice among emergency physicians in general, senior trainees use them significantly more than the other 2 groups, with a mean of 3.59 (SD 1.02),

as opposed to 2.03 (SD 1.21) for junior trainees and 2.23 (SD 1.19) for consultants.

\section{Qualitative Analysis of Open-Ended Questions}

The survey contained several open-ended questions and, although they did not form part of the compulsory sections, still attracted a considerable number of spontaneous and insightful comments. 
In terms of the length of time physicians have been experiencing information overload, $39.6 \%(40 / 101)$ claimed that the phenomenon had increased in the last $5 / 6$ years; $10.9 \%(11 / 101)$ confirmed that it started before that, about 10 to 15 years ago; and $14.9 \%(15 / 101)$ did not specify a date but listed aspects such as progressing in their career, noting how the pressure shifted from night shifts only to an all-time problem and overload worsening once the email was firmly established within the NHS. Around $3.0 \%$ (3/101) felt that they did not have enough experience to judge the problem, and the remaining respondents did not comment.

The remaining comments revolved around 2 main themes (Table 7), specifically, the ways in which medical information overload impacts physicians' work and various preventative measures to overcome information overload. The 5 subthemes identified within each of the 2 main themes are discussed below.

Table 7. Overview of the themes and subthemes emerging from open-ended questions.

\begin{tabular}{|c|c|}
\hline Theme and subthemes & Strands \\
\hline \multicolumn{2}{|c|}{$\begin{array}{l}\text { Ways in which medical information overload impacts on clinicians' } \\
\text { working life }\end{array}$} \\
\hline \multicolumn{2}{|l|}{ 1. Positive impact } \\
\hline & Reverse views \\
\hline \multicolumn{2}{|c|}{ 2. Direct causes leading to reduced patient care } \\
\hline & Impact on patients \\
\hline & Distraction and forgetfulness \\
\hline & Confusion \\
\hline & Delayed decision making \\
\hline & Tiredness, stress, and anxiety \\
\hline \multicolumn{2}{|c|}{ 3. Indirect causes leading to reduced patient care } \\
\hline & Lack of time \\
\hline & Email handling \\
\hline & Information and communication technology systems \\
\hline & Breadth of information \\
\hline & Guidelines and evidence-based practice \\
\hline & Ability to stay up to date \\
\hline & Seniority \\
\hline \multicolumn{2}{|c|}{ Preventative measures to combat information overload } \\
\hline \multicolumn{2}{|l|}{ 4. Personal attitudes } \\
\hline & Avoidance \\
\hline & Therapy \\
\hline & Work-life balance \\
\hline \multicolumn{2}{|c|}{ 5. Workload management } \\
\hline & Email and social media management \\
\hline & Task management \\
\hline & Time management \\
\hline & Prioritization \\
\hline & Delegation \\
\hline
\end{tabular}

\section{RO5: Ways in Which Medical Information Overload Impacts Physicians' Working Life}

\section{Positive Impact}

A total of 3 respondents, all of them consultants, admitted that information overload was indeed present in their working life but did not represent a hindrance to their performance (reverse views subtheme):

It doesn't. You do have be to discerning about where you get information from and use trusted sources though. 
Increase in research is interesting and gives more confidence in decision-making. I find this is helpful rather than a hindrance.

The more information I have the better I can do my $J O B !$

The majority of respondents however did not agree with this view and listed a series of impeding aspects, which can be divided into direct and indirect causes leading to a reduction in patient care.

\section{Direct Causes Leading to Reduced Patient Care}

Among the direct causes, concerns for the well-being and quality of care of patients (impact on patients strand) were the most mentioned and most concerning for the physicians:

On a busy shift on the shop floor when there are competing priorities for my attention, increasingly feel that this means if I try to see my own patients then I either give them poor care or lose control of the department.

Slow decision-making, increased risk of errors.

This continuous feeling of apprehension and an impending sense of loss of control are accompanied by distraction and forgetfulness, which was the second most reported issue (strand) caused by information overload and can be summarized in the quote below:

I have a significantly higher background level of anxiety at work due to concerns about giving poor advice or forgetting something important due to the volume of information I am trying to process. I find the non-shop floor information much less of a problem.

Other strands, such as confusion with the information received, delayed decision making and tiredness, stress, and anxiety were mentioned in equal measure as contributing to a potentially reduced patient's quality of care:

Toward the end of the shift my answers take longer to arrive at, I feel like I am even more risk averse and at times feel like I am can become short with staff asking for help.

During busy environments if documents/protocols contain too much information I may struggle to pick up salient points.

\section{Indirect Causes Leading to Reduced Patient Care}

Among the indirect causes of information overload, leading to a reduced quality of patient care, lack of time to review the information properly was reported as one of the most serious problems:

\section{Huge amount of information coming in and little time} to process and implement any actions needed.

Not enough time to document all relevant information consistently.

Email handling and problems with ICT systems were reported as common, overpowering, and frustrating:

Email mainly - almost overwhelming.
Vast numbers of irrelevant or barely relevant emails containing information which will be forgotten immediately as it concerns rare circumstances or conditions never before experienced (and therefore poorly understood).

Multiple IT systems with different passwords and access. Constant emails - usually not relevant. Feel overwhelmed by the day to day IT so I don't want to access online resources to broaden my knowledge.

Moreover, 3 additional strands, namely guidelines and evidence-based medicine, ability to stay up-to-date, and breadth of information, are related to the need to be informed that physicians experience on a daily basis [50] and are difficult to address in an environment overloaded with what seems like irrelevant information:

Ifeel I am unable to keep up to date with the multitude of clinical guidelines from NICE, the college...only exacerbate by looking at Tweeter!

The number of guidelines/policies that now exist both locally and nationally - it is hard to keep track of all of these.

Finally, seniority was also mentioned as a hindering factor contributing to information overload, as more junior staff and nurses (and patients) tend to direct their queries and doubts to the more experienced physicians:

\section{More difficult out of hours/weekends when I am the only senior decision-maker in the department. If working with a good registrar this can lessen the impact but if working with a less experienced middle grade all questions/information comes though me. \\ Questions from juniors and other colleagues. \\ Lots of questions asked throughout shift from nurses to other doctors. \\ Preventative Measures to Combat Information Overload}

When it comes to addressing and solving the problem of information overload in effective ways, respondents suggested solutions that can be classified into 2 subthemes: personal attitudes and workload management strategies.

\section{Personal Attitudes}

As part of the individual attitudes observed, some physicians simply ignored the problem (avoidance strand). Some other physicians adopted a very pragmatic approach and had no difficulties recognizing their own limits:

When I am at work and feeling overloaded, I step away from the situation.

Learn to ignore.

Acceptance that you can't do everything.

Psychological stress is increasingly recognized within the medical profession, particularly in emergency medicine [51], and some respondents prefer to rely on formal support in the form of therapy: 
Therapy - I have had CBT sessions and NLP sessions to help me deal with the stress and anxiety information overload gives me and to gain strategies regarding how to cope with this.

I take little steps and with the help of my therapist I try not to compare myself negatively to others.

Others preferred to self-manage and find a more balanced relationship between working and personal life (work-life balance strand), although often long shifts and complex working patterns make this option fairly difficult to attain:

My days off are for fun and time away - I do not work on days off. I avoid seeing colleagues on these days who talk about work when they are not there.

I feel a lot of the 'critical information' I need for my day to day job is limited - especially while trying to revise for exams, the need to switch off and rest is very important.

\section{Workload Management}

Physicians have also indicated a number of strategies to manage information overload that are more strictly linked to practical workload management and dealing effectively with emails and social media (email and social media management strand). This appeared to be a priority for many respondents:

\section{When I am not at work or feeling overloaded I ignore my e-mails and mute my social media accounts. \\ Nil work emails on phone mute work WhatsApp groups when on leave no longer active on Facebook at all due to general overload but also work based groups.}

This was followed by strategies to address task and time management in an effective and sustainable way:

Keeping a to-do- list booklet.

Summarising things. Writing things down properly helps consolidate my head.

Finally, prioritization and delegation were also mentioned as effective ways of managing information overload, particularly at times of crisis:

Prioritisation and having some "IT free" time is vital.

Delegation of clinical supervision.

\section{Discussion}

\section{RO1: Determine the Extent to Which Emergency Medicine Physicians Experience Medical Information Overload}

Both quantitative and qualitative data have shown that emergency physicians are deeply affected by an ever-increasing amount of medical information impacting every aspect of their job. The 24/7 (or always available) culture places itself firmly at the heart of the problem, as identified by Walton [45], and leads to problems with fatigue and, consequently, with performance, productivity, and safe decision making [52]. All these aspects have been highlighted by physicians in this study as being compromised not just by the very fast-moving pace typical of their job, but by the constant and relentless information received and the information requested from them. What emerged very clearly from this study is the difficulty in striking a balance between the need to maintain an acceptable and current level of knowledge and the ability to sift and discriminate through large amounts of irrelevant information. There are valid arguments supporting both the benefits of information overload and its drawbacks. A small outlier group of respondents composed of 3 consultants claimed how there was no such thing as information overload as a negative attribute of their job. They see information as an opportunity to learn, as observed by Falschlunger [21], and increase their confidence in their decisions, in line with the freedom of choice described by Brehm and Brehm [53] and De Angelis [54]. However, the majority of physicians perceived information overload as a negative concept hindering their ability to process information effectively and accurately [55]. The migration toward big data handling by health care professionals because of the information expansion phenomenon described by Yamamoto [30] is also reflected in this study as physicians are faced with multiple evolving environments. The increasing number of emails and social media notifications received daily and regular updates in policies and evidence-based practice, coupled with new or updated IT systems to keep abreast of, will all contribute to feelings of inadequacy and frustration. Unless controlled and harnessed, such feelings, in the long term, can lead to burnout syndrome, which is very common among all types of health care professionals $[43,44]$. It is difficult to establish when physicians have started experiencing the burden of information overload in their careers. It appears that consultants and people working in emergency departments the longest have noticed a steady increase, made sharper since the ready access to internet-based resources and emails started over 20 years ago. This is in line with findings by Roetzel [56], who reported how the research around the 1980s and, particularly, the 1990s coincided with the rise and spread of information technologies. However, for most, the problem started to take shape with the advent of mobile platforms and the deployment of electronic health record systems in NHS trusts in 2005 [57].

\section{RO2: Establish the Contributory Factors to Information Overload and Evaluate Their Impact on Physicians' Working Life}

The leading causes of information overload in emergency physicians are multiple, and it is often difficult to discriminate among them because of their interlinked nature. The PCA conducted on the survey statements revealed 3 main factors contributing to information overload. The main factor leading to the concept of the dutiful physician is the administrative tasks physicians must carry out as part of their daily routine, such as reporting, responding to emails, and communicating with the other physicians forming a patient's care team. This study has reported an increased burden because of email handling compared with Walton's [45] research on hospital doctors, leading to the conclusion that, in the last 6 years, since that study was published, the number of emails has significantly increased as part of physicians' daily duties. It is also clear that administrative tasks are one of the main causes of physicians' burnout syndrome [58] because of their persistent and repetitive 
nature. However, physicians are also aware of the importance of carrying out such tasks for the smooth running of the ward and the good care of patients [26]. A second set of causes deeply affecting physicians' perceptions of information overload is linked to the consultation of local and national clinical guidelines. Ironically, such guidelines, as important as they are to guarantee patients' consistency of care, are also a burden to health care professionals because of their frequent updates and notifications. On the one hand, physicians must remain current (ie, the informed physician) and follow the policies and directives reported in the guidelines to guarantee the quality of patient care, but on the other hand, the pressure of being up to date and making sure nothing is overlooked plays a considerable role in increasing physicians' stress [59]. A third factor contributing to information overload entails the number of notifications and alerts received mostly via social media, but also from journal editors and publishers and regarding new medical approaches, clinical trials, discoveries, and case studies (the current physician). These sources have registered a significant increase since Walton's study [45] in 2014, likely because of the current much wider diffusion of social media platforms in all aspects of society. Once again, physicians experience an internal dispute about when to start ignoring such alerts. Maggio and Artino [59] believe that medical librarians could help battle physicians' information overload and help them navigate through the various systems and social media, but they are not utilized as much as they should, a conclusion corroborated by this study, where librarians score among the least useful sources of medical information (Table 2). However, regardless of the causes of information overload, the consequences can be summarized as directly or indirectly leading to reduced patient care, which will be discussed further below.

\section{RO3: Identify the Coping Mechanisms Adopted by Emergency Medicine Physicians to Respond to Information Overload}

To help mitigate information overload, physicians have devised strategies for managing and filtering available medical information. The results of this study have shown similar results and led to the conclusion that information overload prevention and mitigation are left entirely in the hands of individuals and their personal views and preferences. A number of actions are taken from a pragmatic point of view (workload management) quite regularly, but with varying degrees of success. Among the most common approaches, email and social media handling skills are highly desirable, considering the steadily growing amount of communication, including patient information, passing through these tools [60]. Strictly linked to this is also the ability to prioritize tasks (including emails and social media), appearing very high in the list of possible solutions, particularly in situations of multiple concurrent demands [33], which are common practices in emergency departments. Prioritization is a skill developed with time and experience [61], in situations of high demand and variable workload [34], and is particularly popular in emergency departments. Task, time, and information management are other measures frequently adopted by physicians to overcome medical information overload and can take the form of simple actions, such as keeping daily and weekly to-do lists, maintaining written records, timing actions, summarizing information, or key articles to help consolidate knowledge. Although most of the above points were identified by Walton [45], in this study, their importance is stressed further, and new approaches have emerged, including those dictated by personal attitudes. These play an important role in determining how people deal with information overload. This study has highlighted a few approaches, although not all adopted with the same conviction. A small group of respondents admitted that the easiest way is to ignore circumstances or demands when feeling overloaded, which is not necessarily a positive action to undertake, particularly in emergency care. This is symptomatic of the difficulty and pressure physicians are subject to and is a common self-preservation mechanism triggered by overwhelming situations [62]. Other people have mentioned formal therapy and a better work-life balance in which working and private life are kept separate, and personal time is seen as an opportunity to regain strength and stability. These approaches are not new, nor specific to emergency physicians, as they are common to most workplaces $[11,19]$, but it would be advisable to integrate them with formal training on the job and regular sessions on developing coping skills.

\section{RO4: Explore Whether Emergency Medicine Physicians at Different Career Stages Respond to Information Overload in Different Ways}

This part of the study offers a new viewpoint of medical information overload drawn from physicians' experiences at different times in their careers and highlights deeply diverse perceptions and needs.

The study revealed an overall homogeneity of perceptions of medical information overload, in the sense that most respondents agreed on its increasing presence, size, and impact. However, some specific aspects showed differences in responses depending on the seniority of the physician. For example, people who have been in emergency care for 10 years or longer appeared to resent the increased number of emails received and attributed more importance to the ability to handle them than people who have been working in emergency care for less than ten years. This is also in line with the independent sample $t$ tests conducted on the age of the respondents and with the ANOVA tests conducted on the level of employment. However, younger physicians and trainees appeared to be more worried about the loss in social life, impaired decision making, and imprecise clinical judgment than older colleagues and consultants. The literature demonstrates that junior clinicians have higher levels of anxiety because of uncertainty than senior clinicians $[63,64]$, and this is reproduced in this study because of the additional stress of information overload. In particular, it appears that senior trainees are the most concerned about this problem and are the most affected by it, particularly with respect to impaired decision making. A recent study on Canadian emergency medicine residents [65] revealed how junior trainees are properly supervised and supported, but when they then become senior trainees, they lose most of that support and are left to fend for themselves. In addition, senior trainees are at a very demanding stage in their career, where they are preparing for independent practice [66] and are entrusted with more complex decisions 
than ever before. This is bound to contribute to an increased sense of unease and frustration when it comes to information overload.

\section{RO5: Determining the Impact of Physicians' Information Overload on Patient Care}

Compromising the quality of patient care represents the ultimate consequence of medical information overload and rests at the forefront of physicians' thoughts. The qualitative responses in this study reported on the physicians' perceptions of the problem and showed how slow decision making because of information overload and frequent interruptions can lead to substandard care and errors in diagnoses and prescriptions. In addition, remembering patient diagnostics and medical history becomes difficult throughout a shift because of the large amount of information acquired about other cases and other confounding factors [28]. The fast turnover of emergency departments implies that there can often be a queue of people waiting to speak to a physician, who frequently does not manage to action one of these requests before others come in, hence compromising patient safety [32]. Among the effects of information overload mentioned by the respondents, distraction and tiredness play a key role. Physicians experience a higher background level of anxiety at work because of concerns about giving poor advice or forgetting something important because of the volume of information they are trying to process. This is exacerbated by long shifts, which can leave physicians both mentally and physically drained $[43,44]$. In critical situations, finding the right information fast is essential, but information overload can prevent this. Some respondents have been struggling with the correct information they should follow, as sometimes a lot of vague or unclear guidelines or advice can be worse than none at all, whereas others complained that documents and protocols contained so much information that it was difficult to discern salient points. In addition to this, other less obvious causes can still lead to poor patient care, particularly the ubiquitous nature of digital technologies, which provoke conflicting feelings among health care professionals. They are perceived as intrusive and time-consuming, but also as an important resource of clinical information, particularly when dealing with emergencies [31]. A recent study by Laker et al [28] introduced the concept of emphasis framing to aid health care professionals toward a more focused approach to decision making. This cognitive process could help in identifying the most relevant components of any piece of information while discarding the rest. For example, physicians could be directed toward article abstracts rather than full papers or be alerted to an incorrectly entered value for a medication prescription. The study reported an increase in clinical decision-making time through this approach, but also a significantly improved quality of medical decisions. Although a lot of work needs to be done to properly assess the real benefits of emphasis framing and how to implement it in real-world workflows, it is a research direction worth exploring further.

\section{Conclusions}

This study reported on the high and ever-increasing medical information overload in emergency medicine departments in the UK NHS trusts. Among the many factors listed by physicians as influencing information overload, the historical emergency medicine culture of being constantly available throughout a shift (24/7 culture), email, and multidisciplinary communications have been mentioned as being the most severe. However, different levels of employment, experience in emergency medicine, and age also seem to influence physicians' perceptions of the leading causes of information overload. Nevertheless, some information is critical to guarantee high standards of patient care, particularly those derived from clinical guidelines.

This study advances previous research on information overload in 4 distinct ways: (1) by identifying the current causes affecting UK emergency medicine while also recognizing key information sources; (2) by offering insights on how information overload affects physicians in relation to demographic factors such as age, years spent in emergency medicine, and level of employment (ie, seniority); (3) by identifying mechanisms that emergency physicians put in place to manage information overload; and finally (4), by categorizing influencing factors in terms of their impact on patient care and reports on preventative measures currently in use to combat information overload.

However, this study is also subject to the following limitations: (1) although survey is an effective method to receive responses from a large number of participants and to explore relationships between variables, it might be less effective to answer complex questions such as user perceptions of information overload, contributing factors, and coping mechanisms, particularly when limited previous studies were conducted on this topic and with this particular user group; (2) the sample size is limited, although studies conducted on health care professionals are usually affected by this problem; (3) some of the variables listed as potential sources of information overload can be difficult to uniquely discriminate from each other (eg, emails may include clinical guidelines, employer information, and patient information), but the survey wanted to offer both information content aspects and information source channels; and (4) the study was only able to assess physicians' perceptions on the impact that information overload has on the quality of patient care. To attain an objective measure of such impact, different indicators would have been needed to allow for a direct correlation between patients' health outcomes and physicians' information overload.

This study has identified further research areas that could be worth taking forward to provide a more in-depth and more informed insight into information overload. The 24/7 culture, multidisciplinary interactions, and the pressure of following relevant guidelines are aspects specific to the emergency medicine profession and must be addressed to relieve physicians. Further investigation could determine the influence of professional boundaries on such aspects. A consistent thread in the findings was the contribution made by email in increasing information overload. This was an interesting outcome where it could be assumed that social media as a communication channel was taking the place of email. This would point to the value of a more detailed exploration, specifically on email and information overload. An area of concern that this study established was the interrelationship between clinical guidelines and information overload. By establishing how clinical guidelines make this contribution, it is possible to determine 
how presentation, style, and format could be adapted to make them more accessible.

NHS trusts in the United Kingdom should consider some of the strategies adopted by the physicians participating in this study to reduce the burden of information overload (eg, prioritization) and try to embed routine training or guidance on time and information management skills in staff development programs.

\section{Conflicts of Interest}

None declared.

\section{References}

1. Blair A. Too Much To Know: Managing Scholarly Information Before the Modern Age. Yale: Yale University Press; 2010.

2. Horrigan J. Information Overload. Pew Research Center. 2016. URL: https://www.pewresearch.org/internet/2016/12/07/ information-overload/ [accessed 2020-03-11]

3. Information Recall: The Secret Weapon You Didn't Know You Needed. TeleWare. URL: https://www.teleware.com/ wp-content/uploads/2018/04/TeleWare ReCall White Paper.pdf [accessed 2020-02-03]

4. Dadashi N, Golightly D, Sharples S. Seeing the woods for the trees: the problem of information inefficiency and information overload on operator performance. Cogn Tech Work 2017 Nov 23;19(4):561-570 [FREE Full text] [doi: 10.1007/s10111-017-0451-1]

5. Floridi L. The Fourth Revolution: How the Infosphere is Reshaping Human Reality. Oxford, UK: Oxford University Press; 2014.

6. Toffler A. Future Shock. New York, USA: Bantam Books; 1970.

7. Schick A, Gordon L, Haka S. Information overload: a temporal approach. Account Organ Soc 1990 Jan 1;15(3):199-220 [FREE Full text] [doi: 10.1016/0361-3682(90)90005-f]

8. Hall A, Walton G. Information overload within the health care system: a literature review. Health Info Libr J 2004 Jun;21(2):102-108 [FREE Full text] [doi: 10.1111/j.1471-1842.2004.00506.x] [Medline: 15191601]

9. Benselin J, Ragsdell G. Information overload: the differences that age makes. J Libr Inf Sci 2016 Jul 8;48(3):284-297 [FREE Full text] [doi: $10.1177 / 0961000614566341]$

10. Jackson T, Farzaneh P. Theory-based model of factors affecting information overload. J Glob Inf Manag 2012 Dec;32(6):523-532 [FREE Full text] [doi: 10.1016/j.ijinfomgt.2012.04.006]

11. Joining the Dots: Decision Making for a New Era. Chartered Global Management Accountant. 2016. URL: https://www. cgma.org/content/dam/cgma/resources/downloadabledocuments/joining-the-dots-report.pdf [accessed 2020-03-11]

12. Abdullah N, Mustapar N. Heart rate reading patterns of moment of information overload during online information searching. J ICT 2019 Jul;18(3):233-251 [FREE Full text] [doi: 10.32890/jict2019.18.3.1]

13. Borkovich D, Middle G. Information overload revisited: infinite organizational threats. Issues Info Sys 2018;19(4):150-161 [FREE Full text]

14. Hwang M, Hong J, Tai K, Chen J, Gouldthorp T. The relationship between the online social anxiety, perceived information overload and fatigue, and job engagement of civil servant LINE users. Gov Inf Q 2020 Jan;37(1):101423 [FREE Full text] [doi: 10.1016/j.giq.2019.101423]

15. Whelan E, Islam A, Brooks S. Applying the SOBC paradigm to explain how social media overload affects academic performance. Comput Educ 2020 Jan;143:103692 [FREE Full text] [doi: 10.1016/j.compedu.2019.103692]

16. Yin P, Ou CX, Davison RM, Wu J. Coping with mobile technology overload in the workplace. Internet Res 2018 Oct 2;28(5):1189-1212. [doi: 10.1108/intr-01-2017-0016]

17. Joyce S, Shand F, Bryant RA, Lal TJ, Harvey SB. Mindfulness-based resilience training in the workplace: pilot study of the internet-based resilience at work (RAW) mindfulness program. J Med Internet Res 2018 Sep 11;20(9):e10326 [FREE Full text] [doi: 10.2196/10326] [Medline: $\underline{\text { 30206055] }}$

18. Szóstek A. 'Dealing with my emails: latent user needs in email management. Comput Hum Behav 2011 Mar 1;27(2):723-729 [FREE Full text] [doi: 10.1016/j.chb.2010.09.019]

19. Jackson T, Burgess A, Edwards J. A Simple Approach to Improving Email Communication: Going Back to Basics. CORE - Aggregating the World's Open Access Research Papers. 2006. URL: https://dl.acm.org/doi/pdf/10.1145/1132469.1132493 [accessed 2020-03-11]

20. Kalman Y. Why do we blame information for our overload? In: Work Pressures. New York, USA: Routledge; 2016.

21. Falschlunger L, Lehner O, Treiblmaier H. InfoVis: The Impact of Information Overload on Decision Making Outcome in High Complexity Settings. In: Proceedings of the 2016 CHI Conference on Human Factors in Computing Systems. 2016 Presented at: CHI'16; May 7-12, 2016; San Jose, USA URL: https://aisel.aisnet.org/sighci2016/3

22. Kumar A, Faiq M, Pandey S, Pareek V, Mochan S, Kumar P, et al. Addictive influences and stress propensity in heavy internet users: a proposition for information overload mediated neuropsychiatric dysfunction. Curr Psychiatr Rev 2018 Feb 20;13(4):293-300 [FREE Full text] [doi: 10.2174/1573400513666170728155836]

23. Melby L, Toussaint P. Supporting Operating Nurses' Collaborative Work: Preventing Information Overload and Tailoring Information Access. In: Proceedings of the IEEE Symposium on Computer-Based Medical Systems. 2009 Presented at: 
CBMS'09; August 3-4, 2009; Albuquerque, New Mexico, USA URL: https://doi.org/10.1109/CBMS.2009.5255364 [doi: $10.1109 / \mathrm{cbms} .2009 .5255364]$

24. Wisner K, Lyndon A, Chesla CA. The electronic health record's impact on nurses' cognitive work: an integrative review. Int J Nurs Stud 2019 Jun;94:74-84. [doi: 10.1016/j.ijnurstu.2019.03.003] [Medline: 30939418]

25. Marbouti M, Maurer F. Social Media Use During Emergency Response - Insights from Emergency Professionals. In: Proceedings of the Conference on e-Business, e-Services and e-Society. 2016 Presented at: I3E'16; September 13-15, 2016; Swansea, United Kingdom URL: https://doi.org/10.1007/978-3-319-45234-0_49 [doi: 10.1007/978-3-319-45234-0_49]

26. Walter SR, Raban MZ, Dunsmuir WT, Douglas HE, Westbrook JI. Emergency doctors' strategies to manage competing workload demands in an interruptive environment: an observational workflow time study. Appl Ergon 2017 Jan;58:454-460. [doi: 10.1016/j.apergo.2016.07.020] [Medline: 27633242]

27. Klerings I, Weinhandl AS, Thaler KJ. Information overload in healthcare: too much of a good thing? Z Evid Fortbild Qual Gesundhwes 2015;109(4-5):285-290. [doi: 10.1016/j.zefq.2015.06.005] [Medline: 26354128]

28. Laker L, Froehle C, Windeler J, Lindsell C. Quality and efficiency of the clinical decision-making process: information overload and emphasis framing. Prod Oper Manag 2017 Oct 2;27(12):2213-2225 [FREE Full text] [doi: 10.1111/poms.12777]

29. Walter S, Dunsmuir W, Westbrook J. Studying interruptions and multitasking in situ: the untapped potential of quantitative observational studies. Int J Hum Comput Stud 2015 Jul 1;79:118-125 [FREE Full text] [doi: 10.1016/j.ijhcs.2015.01.008]

30. Yamamoto Y. Healthcare and the roles of the medical profession in the big data era. Japan Med Assoc J 2016 Sep;59(2-3):125-139 [FREE Full text] [Medline: 28299246]

31. Fernandes CO, Miles S, Lucena CJ, Cowan D. Artificial intelligence technologies for coping with alarm fatigue in hospital environments because of sensory overload: algorithm development and validation. J Med Internet Res 2019 Nov 26;21(11):e15406 [FREE Full text] [doi: 10.2196/15406] [Medline: $\underline{\text { 31769762] }}$

32. Connell A, Black G, Montgomery H, Martin P, Nightingale C, King D, et al. Implementation of a digitally enabled care pathway (part 2): qualitative analysis of experiences of health care professionals. J Med Internet Res 2019 Jul 15;21(7):e13143 [FREE Full text] [doi: 10.2196/13143] [Medline: $\underline{\text { 31368443] }}$

33. Diniz V, Borges M, Gomes J, Canós J. Decision making support in emergency response. In: Encyclopedia of Decision Making and Decision Support Technologies. New York, USA: IGI Global; 2008:184-191.

34. Westbrook JI, Raban MZ, Walter SR, Douglas H. Task errors by emergency physicians are associated with interruptions, multitasking, fatigue and working memory capacity: a prospective, direct observation study. BMJ Qual Saf 2018 Aug;27(8):655-663 [FREE Full text] [doi: 10.1136/bmjqs-2017-007333] [Medline: 29317463]

35. Levin S, France D, Hemphill R, Jones I, Chen K, Rickard D, et al. Tracking workload in the emergency department. Hum Factors 2006;48(3):526-539. [doi: 10.1518/001872006778606903] [Medline: 17063967]

36. Liadova A, Korkiya E, Mamedov A, Panich N. The burnout among emergency physiciansvidence from Russia (sociological study). Man India 2017;97(15):495-507 [FREE Full text]

37. Schooley B, Hikmet N, Tarcan M, Yorgancioglu G. Comparing burnout across emergency physicians, nurses, technicians, and health information technicians working for the same organization. Medicine 2016 Mar;95(10):e2856 [FREE Full text] [doi: 10.1097/MD.0000000000002856] [Medline: 26962780]

38. Ellahi A, Mushtaq R. Doctors at risk of job burnout, diminishing performance and smoking habits. J BSA Med Soc Group 2012;6(3):36-47.

39. Burn-out an 'Occupational Phenomenon': International Classification of Diseases. World Health Organization. 2019. URL: https://www.who.int/mental_health/evidence/burn-out/en/ [accessed 2020-03-09]

40. Shanafelt TD, Mungo M, Schmitgen J, Storz KA, Reeves D, Hayes SN, et al. Longitudinal study evaluating the association between physician burnout and changes in professional work effort. Mayo Clin Proc 2016 Apr;91(4):422-431. [doi: 10.1016/j.mayocp.2016.02.001] [Medline: 27046522]

41. Lemaire JB, Wallace JE. Burnout among doctors. Br Med J 2017 Jul 14;358:j3360. [doi: 10.1136/bmj.j3360] [Medline: 28710272]

42. Nmadu A, Omole V, Oyefabi A, Usman N, Igboanusi C, Gobir A, et al. Physician burnout: an overview. J Res Basic Clin Sc 2019 Mar 28;1(1):111-114 [FREE Full text]

43. Hauck S, Gabbard GO. Institutional factors in the medical burnout epidemic. Braz J Psychiatry 2019;41(2):191-192 [FREE Full text] [doi: 10.1590/1516-4446-2018-0340] [Medline: 30942324]

44. Furlow B. Information overload and unsustainable workloads in the era of electronic health records. Lancet Respir Med 2020 Mar;8(3):243-244. [doi: 10.1016/S2213-2600(20)30010-2] [Medline: 32135094]

45. Walton G. Knowledge Management in the Age of Information Overload. In: Proceedings of the 19th Congress of the European Association of Hospital Pharmacists. 2014 Presented at: EAHP'14; April 8, 2014; Barcelona, Spain URL: https:/ /www.managementstudyguide.com/knowledge-management-in-age-of-information-overload.htm

46. Braun V, Clarke V. What can 'thematic analysis' offer health and wellbeing researchers? Int J Qual Stud Health Well-being 2014;9:26152 [FREE Full text] [doi: 10.3402/qhw.v9.26152] [Medline: 25326092]

47. Kaiser H. An index of factorial simplicity. Psychometrika 1974 Mar;39(1):31-36 [FREE Full text] [doi: 10.1007/bf02291575] 
48. Hellier C, Tully V, Forrest S, Jaggard P, MacRae M, Habicht D, et al. Improving multidisciplinary communication at ward board rounds using video enhanced reflective practice. BMJ Qual Improv Rep 2015;4(1):e [FREE Full text] [doi: 10.1136/bmjquality.u206968.w2801] [Medline: 26734342]

49. Penney G. Adopting and adapting clinical guidelines for local use. Obstet Gynecol 2007 Jan;9(1):48-52 [FREE Full text] [doi: 10.1576/toag.9.1.048.27296]

50. Russell-Rose T, Chamberlain J. Expert search strategies: the information retrieval practices of healthcare information professionals. JMIR Med Inform 2017 Oct 2;5(4):e33 [FREE Full text] [doi: 10.2196/medinform.7680] [Medline: 28970190]

51. Aisling M, Aisling D, David C. An assessment of psychological need in emergency medical staff in the northern health and social care trust area. Ulster Med J 2016 May;85(2):92-98 [FREE Full text] [Medline: 27601762]

52. Banks S, Landon LB, Dorrian J, Waggoner LB, Centofanti SA, Roma PG, et al. Effects of fatigue on teams and their role in 24/7 operations. Sleep Med Rev 2019 Dec;48:101216. [doi: 10.1016/j.smrv.2019.101216] [Medline: $\underline{31630015]}$

53. Brehm S, Brehm J. Psychological Reactance: A Theory of Freedom and Control. New York, USA: Academic Press; 2013.

54. de Angelis M. Choice contexts and social communication. Micro Macro Mark 2017(3):435-456. [doi: 10.1431/88004]

55. Pilli L, Mazzon J. Information overload, choice deferral, and moderating role of need for cognition: empirical evidence. Rev Adm Empres 2016 Jan 1;51(1):36-55 [FREE Full text] [doi: 10.5700/rausp1222]

56. Roetzel P. Information overload in the information age: a review of the literature from business administration, business psychology, and related disciplines with a bibliometric approach and framework development. Bus Res 2018 Jul 6;12(2):479-522 [FREE Full text] [doi: 10.1007/s40685-018-0069-z]

57. Sheikh A, Cornford T, Barber N, Avery A, Takian A, Lichtner V, et al. Implementation and adoption of nationwide electronic health records in secondary care in England: final qualitative results from prospective national evaluation in 'early adopter' hospitals. Br Med J 2011 Oct 17;343:d6054 [FREE Full text] [doi: 10.1136/bmj.d6054] [Medline: 22006942]

58. Ozkula G, Durukan E. Burnout syndrome among physicians: the role of socio-demographic characteristics. J Psychiatry Neurosci 2017 Jun 15;1(30):136-144. [doi: 10.5350/dajpn2017300207]

59. Maggio LA, Artino AR. Staying up to date and managing information overload. J Grad Med Educ 2018 Oct;10(5):597-598 [FREE Full text] [doi: 10.4300/JGME-D-18-00621.1] [Medline: 30377482]

60. Roland D, Brazil V. Top 10 ways to reconcile social media and 'traditional' education in emergency care. Emerg Med J 2015 Oct;32(10):819-822. [doi: 10.1136/emermed-2015-205024] [Medline: 26253148]

61. Garner J, Murray S, Parisaei M. Prioritisation on labour ward. Obstet Gynaecol Reprod Med 2019 Oct;29(10):292-297 [FREE Full text] [doi: 10.1016/j.ogrm.2019.06.004]

62. Fink G. Stress, definitions, mechanisms, and effects outlined: lessons from anxiety. Handbook of Stress Series 2016 Jan;1:3-11 [FREE Full text] [doi: 10.1016/b978-0-12-800951-2.00001-7]

63. Li CJ, Syue YJ, Tsai TC, Wu KH, Lee CH, Lin YR. The impact of emergency physician seniority on clinical efficiency, emergency department resource use, patient outcomes, and disposition accuracy. Medicine (Baltimore) 2016 Feb;95(6):e2706 [FREE Full text] [doi: 10.1097/MD.0000000000002706] [Medline: 26871807]

64. Bovier PA, Perneger TV. Stress from uncertainty from graduation to retirement--a population-based study of Swiss physicians. J Gen Intern Med 2007 May;22(5):632-638 [FREE Full text] [doi: 10.1007/s11606-007-0159-7] [Medline: 17443371]

65. Kilbertus S, Pardhan K, Zaheer J, Bandiera G. Transition to practice: evaluating the need for formal training in supervision and assessment among senior emergency medicine residents and new to practice emergency physicians. CJEM 2019 May;21(3):418-426. [doi: 10.1017/cem.2019.8] [Medline: 30841941]

66. Sebok-Syer SS, Chahine S, Watling CJ, Goldszmidt M, Cristancho S, Lingard L. Considering the interdependence of clinical performance: implications for assessment and entrustment. Med Educ 2018 Apr 19;52:970-980 [REE Full text] [doi: 10.1111/medu.13588] [Medline: 29676054]

\author{
Abbreviations \\ ANOVA: analysis of variance \\ EMP: emergency medicine physician \\ ICT: Information and Communication Technology \\ IT: information technology \\ NHS: National Health Service \\ PCA: principal component analysis \\ WHO: World Health Organization
}


Edited by G Eysenbach; submitted 04.04.20; peer-reviewed by X Lu, Y Zhang, R Guo; comments to author 11.05.20; revised version received 22.05.20; accepted 11.06.20; published 27.07 .20

Please cite as:

Sbaffi L, Walton J, Blenkinsopp J, Walton G

Information Overload in Emergency Medicine Physicians: A Multisite Case Study Exploring the Causes, Impact, and Solutions in Four North England National Health Service Trusts

J Med Internet Res 2020;22(7):e19126

URL: http://www.jmir.org/2020/7/e19126/

doi: $\underline{10.2196 / 19126}$

PMID: $\underline{32716313}$

CLaura Sbaffi, James Walton, John Blenkinsopp, Graham Walton. Originally published in the Journal of Medical Internet Research (http://www.jmir.org), 27.07.2020. This is an open-access article distributed under the terms of the Creative Commons Attribution License (https://creativecommons.org/licenses/by/4.0/), which permits unrestricted use, distribution, and reproduction in any medium, provided the original work, first published in the Journal of Medical Internet Research, is properly cited. The complete bibliographic information, a link to the original publication on http://www.jmir.org/, as well as this copyright and license information must be included. 